\title{
Comparison of the embryo survival rate in heifers following artificial insemination, non-surgical blastocyst transfer or both
}

\author{
J. M. Sreenan and T. McDonagh \\ The Agricultural Institute, Belclare, Tuam, Co. Galway, Ireland
}

\begin{abstract}
Summary. In Exp. 1, embryo survival rates of 45 and $47 \%$ were recorded after artificial insemination and ipsilateral transfer respectively. In Exp. 2, pregnancy rates of 62 and $60 \%$ were recorded after artificial insemination and contralateral transfer to inseminated recipients respectively. In this experiment the contralateral transferred embryo survival rate was $44 \%$. Transferred embryo survival was lower overall when donors and recipients were out of phase by 1 day than when exactly synchronous.
\end{abstract}

\section{Introduction}

Pregnancy and embryo survival rates in the cow following non-surgical transfer of embryos have generally been low but inconsistent (see review by Sreenan, 1978). The most common method now used for non-surgical transfer is the Cassou artificial insemination gun (Sreenan, 1975b; Boland, Crosby \& Gordon, 1975; Renard, Heyman \& du Mesnil du Buisson, 1977; Newcomb, Christie \& Rowson, 1978). After ipsilateral non-surgical transfer of a single embryo, survival rates of 31 to $60 \%$ have been reported (Greve, Lehn-Jensen \& Rasbech, 1978; Brand, Aarts, Zaayer \& Oxender, 1978; Sreenan, 1978), while rates of $24-40 \%$ have been reported after contralateral non-surgical transfers to previously inseminated recipients (see Sreenan, 1978).

In none of these studies have inseminated animals been used as controls. The present studies were therefore undertaken to compare the pregnancy and embryo survival rates resulting from ipsilateral non-surgical transfer, contralateral non-surgical transfer to previously inseminated recipients and artificial insemination of control animals.

\section{Materials and Methods}

Hereford-cross heifers within a weight range of 310-391 kg were used. The oestrous cycles of 109 heifers were synchronized by treatment with intravaginal progesterone-impregnated pessaries for 10 days (Sreenan, 1975a). The occurrence of oestrus following treatment was detected with the aid of vasectomized bulls and only heifers observed in standing oestrus were used.

The induction of superovulation and collection of blastocysts from donor heifers were similar for both experiments and carried out as previously described (Sreenan, 1975b). The medium for collection and subsequent transfer was phosphate-buffered saline (Whittingham, 1971). Blastocysts were collected between Days 9 and 13 inclusive of the oestrous cycle (day of oestrus $=$ Day 0). All transfers were carried out between 2 and $7 \mathrm{~h}$ after blastocyst collection to recipients whose cycles were synchronous $(0 \pm 1$ day $)$ with those of the donors. Transfers were carried out using a Cassou artificial insemination gun $(0.25 \mathrm{ml}$ straw). The straw, gun and outer sheath were sterilized before transfer and no vaginal specula were used. Introduction of the Cassou A.I. gun was carried out as for artificial insemination, care being taken to remove the 
gun from a sterile package and pass it quickly into the vagina. The recipients had the vulval area first cleaned with a dry swab but no other washing or treatment of recipients was carried out.

Embryo survival in the heifers was assessed after slaughter at Days 30-42 inclusive from the synchronized oestrus. Survival rate was based on the recovery of viable fetuses only. In Exp. 1, animals showing standing oestrus were randomly allotted to receive artificial insemination or non-surgical ipsilateral transfer. Artificial insemination was carried out using frozen-thawed semen $\left(\sim 30 \times 10^{6}\right.$ total spermatozoa/straw). Inseminations were carried out between 6 and $10 \mathrm{~h}$ after the observed onset of standing oestrus.

In Exp. 2, all animals were artificially inseminated as described above and about half of these were randomly allotted to receive contralateral non-surgical embryo transfer.

\section{Results}

There was no difference in the embryo survival rate following artificial insemination or ipsilateral transfer in Exp. 1 (Table 1).

Table 1. Embryonic survival in heifers following artificial insemination or ipsilateral non-surgical transfer (Exp. 1)

\begin{tabular}{ccccccc}
\hline & \multicolumn{2}{c}{ Inseminated controls } & & \multicolumn{2}{c}{ Non-surgical transfers } \\
\cline { 2 - 3 } \cline { 6 - 7 } Replicate & $\begin{array}{c}\text { No. of } \\
\text { animals }\end{array}$ & $\begin{array}{c}\text { No. of viable } \\
\text { fetuses (\%) }\end{array}$ & & $\begin{array}{c}\text { No. of } \\
\text { animals }\end{array}$ & $\begin{array}{c}\text { No. of viable } \\
\text { fetuses (\%) }\end{array}$ \\
\hline 1 & 4 & $2(50)$ & & 11 & $5(45)$ \\
2 & 8 & $3(38)$ & & 6 & $3(50)$ \\
3 & 3 & $1(33)$ & & 8 & $5(63)$ \\
4 & 7 & $4(57)$ & & 11 & $4(36)$ \\
\hline Totals & 22 & $10(45)$ & 36 & $17(47)$ \\
\hline
\end{tabular}

In Exp. 2, the proportion of animals pregnant following artificial insemination or a combination of insemination and contralateral transfers was not different (Table 2) but because $44 \%$ of the embryos survived in the transferred group, this resulted in a twin pregnancy rate of $60 \%$ (of pregnant recipients) compared with $0 \%$ in the inseminated controls.

Table 2. Embryonic survival following artificial insemination or contralateral non-surgical transfer to inseminated heifers (Exp. 2)

\begin{tabular}{cccccccc}
\hline & \multicolumn{2}{c}{ Inseminated controls } & & \multicolumn{4}{c}{ A.l. + non-surgical transfers } \\
\cline { 2 - 3 } \cline { 5 - 7 } Replicate & $\begin{array}{c}\text { No. of } \\
\text { animals }\end{array}$ & $\begin{array}{c}\text { No. pregnant } \\
(\%)\end{array}$ & & $\begin{array}{c}\text { No. of } \\
\text { animals }\end{array}$ & $\begin{array}{c}\text { No. pregnant } \\
(\%)\end{array}$ & $\begin{array}{c}\text { No. with twins } \\
(\%)\end{array}$ & $\begin{array}{c}\text { Transferred } \\
\text { embryo survival } \\
(\%)\end{array}$ \\
\hline 1 & 5 & $2(40)$ & & 12 & $8(67)$ & $3(38)$ & $5 *(42)$ \\
2 & 7 & $5(71)$ & & 13 & $7(54)$ & $6(86)$ & $6(46)$ \\
3 & 14 & $9(64)$ & & - & - & - & - \\
\hline Totals & 26 & $16(62)$ & 25 & $15(60)$ & $9(60)$ & $11(44)$ \\
\hline
\end{tabular}

* Two were single contralateral pregnancies.

Embryonic survival of blastocysts transferred out of phase by 1 day ( \pm 1 day) was reduced following both ipsilateral and contralateral transfers. The data in Table 3 are presented for hatched expanded blastocysts only to avoid confounding the possible effect of blastocyst development stage. 
Table 3. Embryonic survival in heifers in relation to donorrecipient synchrony for hatched expanded blastocysts

\begin{tabular}{lrrrrr}
\hline & \multicolumn{3}{c}{ Degree of synchronization (days) } \\
\cline { 2 - 3 } & \multicolumn{2}{c}{$\begin{array}{l}\text { Ipsilateral } \\
\text { transfers }\end{array}$} & & \multicolumn{2}{c}{$\begin{array}{c}\text { Contralateral } \\
\text { transfers }\end{array}$} \\
\cline { 2 - 6 } & 0 & \pm 1 & & 0 & \pm 1 \\
\cline { 2 - 6 } & 15 & 8 & 10 & 11 \\
$\begin{array}{l}\text { No. of animals } \\
\text { Viable fetuses } \\
\quad \text { No. }\end{array}$ & 8 & 3 & & 6 & 4 \\
Percentage & 53 & 38 & 60 & 36 \\
\hline
\end{tabular}

\section{Discussion}

The pregnancy or embryo survival rates recorded following artificial insemination or ipsilateral transfer were not different and the overall survival rate for transferred embryos in this group (47\%) is consistent with other results from this laboratory (Sreenan, 1978). Renard et al. (1977) have also reported a survival rate of $45 \%$ with a similar technique. This survival rate after nonsurgical embryo transfer is also similar to that reported by others: after ipsilateral surgical transfers of single embryos survival rates of $6 / 13(46 \%)$ and $15 / 28(54 \%)$ were obtained by Newcomb \& Rowson (1976) and Tervit, Havik \& Smith (1977) respectively.

The transferred embryo survival rates shown in Table 1 are consistent over 4 separate replicated groups and thus are likely to be repeatable. Following contralateral transfers to previously inseminated recipients, the pregnancy rate $(60 \%)$ was similar to the control group (62\%) and is consistent with other reports in the literature which show that contralateral nonsurgical transfer procedures do not affect the ability of the animal's own embryo to survive (e.g. see Seidel, Bowen, Homan \& Okun, 1975). The contralateral transferred embryo survival rate reported here $(44 \%)$ is encouraging in that it resulted in a twin-pregnancy rate of $60 \%$. Survival rates of contralaterally transferred embryos have generally been reported to be lower than those after ipsilateral transfers. In the data reported here, two embryos survived in the contralateral horn only and are presumed to have been transferred embryos. As suggested by Newcomb, Christie \& Rowson (1978), this would indicate that it is essential to have a high conception rate following the insemination to achieve a high embryo survival in the contralateral horn in previously inseminated animals.

The degree of donor and recipient synchrony affected embryo survival rates in a manner similar to that first shown by Rowson, Moor \& Lawson (1969). In both experiments, the blastocysts were classed according to stage of development but because the numbers in each class were small it was not possible to relate developmental stage at transfer to subsequent survival.

The results from this study suggest that normal pregnancy and embryo survival rates can be achieved following cervical blastocyst transfer to the lower uterine horn between Days 9 and 13 of the oestrous cycle. Placement of the blastocyst in the lower uterine horn ensures least trauma due to movement of the transfer gun.

We thank Mr D. Morris, Mr G. Morris, Mr P. Creaven and Mr S. McHugh for help during this study.

\section{References}

Boland, M.P., Crosby, T.F. \& Gordon, I. (1975) Twinpregnancy in cattle established by non-surgical egg transfer. Br. vet. J. 131, 738-740.

Brand, A., Aarts, M.H., Zaayer, D. \& Oxender, W.D. (1978) Recovery and transfer of embryos by non- surgical procedures in lactating dairy cattle. In Control of Reproduction in the Cow, pp. 281-291. Ed. J. M. Sreenan. Commission of the European Communities, Luxembourg.

Greve, T., Lehn-Jensen, H. \& Rasbech, N.O. (1978) 
Practical application of non-surgical collection of bovine embryos in Danish Pedigree cattle. In Control of Reproduction in the Cow, pp. 363-373. Ed. J. M. Sreenan. Commission of the European Communities, Luxembourg.

Newcomb, R. \& Rowson, L.E.A. (1976) Aspects of the non-surgical transfer of bovine eggs. Proc. $8 \mathrm{th}$ Int. Congr. Anim. Reprod. \& A.I., Krakow, Vol. 3, 262265.

Newcomb, R., Christie, W.B. \& Rowson, L.E.A. (1978) Comparison of the fetal survival rate in heifers after the transfer of an embryo surgically to one uterine horn and non-surgically to the other. J. Reprod. Fert. 52, 395-397.

Renard, J.P., Heyman, Y. \& du Mesnil du Buisson, F. (1977) Unilateral and bilateral cervical transfer of bovine embryos at the blastocyst stage. Theriogenology 74, 189-194.

Rowson, L.E.A., Moor, R.M. \& Lawson, R.A.S. (1969) Fertility following egg transfer in the cow: effect of method, medium and synchronization of oestrus. $J$. Reprod. Fert. 18, 517-523.

Seidel, G.E. Jr., Bowen, J.M., Homan, N.R. \& Okun, M.E. (1975) Fertility of heifers with sham embryo transfer through the cervix. Vet. Rec. 97, 307-308.

Sreenan, J.M. (1975a) Effect of long- and short-term intravaginal progestagen treatments on synchronization of oestrus and fertility in heifers. J. Reprod. Fert. 45, 479-485.

Sreenan, J.M. (1975b) Successful non-surgical transfer of fertilized cows eggs. Vet. Rec. 96, 490-491.

Sreenan, J.M. (1978) Non surgical embryo transfer in the cow. Theriogenology 9, 69-83.

Tervit, H.R., Havik, P.G. \& Smith, J.F. (1977) Egg transfer in cattle: pregnancy rate following transfer to the uterine horn ipsilateral or contralateral to the functional corpus luteum. Theriogenology 7, 3-10.

Whittingham, D.B. (1971) Culture of mouse ova. $J$. Reprod. Fert., Suppl. 14, 7-21.

Received 20 October 1978 